\title{
FERTILISING FARMS AND INSTITUTIONAL AUTHORITIES:
}

\author{
EXPERTS, REgIME-MAKING AND AgRICULTURAL POLITICS IN GREECE, 1945-2000
}

STATHIS ARAPOSTATHIS

National and Kapodistrian University of Athens

\begin{abstract}
The article studies the politics of expertise and the co-production of sociotechnical imaginaries, expertise identities and public policies in agriculture and the use of fertilisers in Greece between the years 1945 and 2000. By applying the concept of the coproductionist idiom, the processes of appropriation will be studied and dynamic processes in postwar Greece are demonstrated. The study argues that experts functioned not only as mediators but as promoters and shapers of sociotechnical imaginaries in Greece, and that they directed specific policies in promoting or controlling the use of fertilisers: particularly nitrogen $(N)$ fertilisers. Until 1990, experts had the power and the authority to politically and socially legitimise the use of intense fertilisation. In the years since 1990, the experts' role was configured by transnational political pressures from the European Union that shaped the experts' consensus on the harmful effects of agriculture malpractice and the overuse of nitrogen fertilisers. Yet still while an environmentally friendly agriculture paradigm was sought the dominant public discourse promoted by experts in Greece still prioritised accuracy and rational use.
\end{abstract}

KEYWORDS: Fertilisers, Greece, environment, pollution, chemistry, expertise

\section{INTRODUCTION}

On 24 April 2015, the daily press reported the condemnation of Greece by the European High Court. ${ }^{1}$ This decision was caused by the incomplete implementation of European legislation and directives in relation to the use of fertilisers, and particularly the overconsumption of nitrogen $(\mathrm{N})$ fertilisers in Greece. Although the Greek state exercised policies to reduce the extensive use of $\mathrm{N}$ fertilisers and their harmful effects to water and soil, the European Union and its institutions believed these measures to be inadequate.

${ }^{1}$ Kathimerini, 24/4/2015. 
The situation led the European High Court to ask for an increase in the number of regions in Greece characterised as "vulnerable zones." In 2010, the European Union had asked the Greek government to include more regions in its list of "vulnerable zones;" however, the official Greek state moved with bureaucratic ambivalence in response to the Union's suggestions. This resulted in the 2015 court case and the country's condemnation.

A year and a half later, in a local-yet historic_-daily journal in the rural area of Larissa in Thessaly, professor of the local university, Fanis Gemtos, argued that precision agriculture should be considered as a remedy to the daily malpractices in farming. He argued that a drastic reduction in the cost of production could be achieved by securing precision in the management of fertilisers, water and propagation material. Through the appropriate use of mechanical and information devices, farming could be transformed into a practice where fertilisation would be conducted through "variable rate inputs." These "variable rate inputs" were formed by taking into account soil and plant conditions, as well as the geographies of the fields and the geomorphology. Together they necessitated a more flexible strategy to the process of fertilization, and that of plant and soil nutrition. Gemtos argued that the surveillance of fields and plants would facilitate variability in the doses of fertilizer required in different fields of the same plain, and even in different parts of the same field. Through mechanization and automation, Gemtos insisted, variability would be lessened, resulting in greater efficiency and a reduction in the cost of fertilisation practices. $^{2}$

In the early years of the twenty first century, other engineers and agronomists promoted a holistic approach to agriculture. They argued that: ${ }^{3}$

The future of European, specifically Greek, agriculture is in the holistic management of agricultural production with nowrecognised quality accreditations and certifications. According to scientists, holistic agricultural management would remedy the drawbacks of conventional agriculture such as the waste of natural resources, and the excessive use of inputs (fertilisers,

2 Fanis Gemtos, "The promises of Accuracy Agriculture for Fertilization," Eleftheria, 31/10/2016.

${ }^{3}$ Dimitrios Tseles, Aspasia Efthymiadou, Maria Goulta,

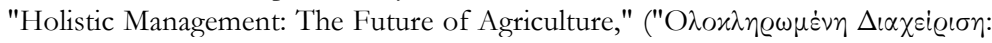

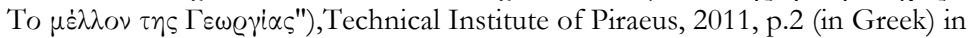

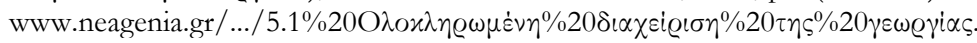
pdf, Accessed 07/11/2016. 
agrochemicals, and energy). Of central importance, though, for the production of high quality agricultural products and environmental protection, is the correct use of inputs mainly of the fertilisers and pesticides that have been criticised for the harmful effects on the environment and the health of consumers.

The holistic management of agricultural resources was promoted as an effective public policy with the means to increase productivity and quality, and to forge a different developmental pathway that would introduce a different approach to agriculture.

In the early twenty first century, the central issue of concern for experts and policy makers was the reduction of agrochemicals, and the "rational" use of $\mathrm{N}$ fertilisers. This arose from concerns about environmental pollution, and its impact on the public health of consumers and rural communities. In this setting the present article aims to address the following research questions:

1. What was the role of experts and knowledge communities in shaping the Greek agriculture regime in relation to the use of fertilisers in post-World War II Greece?

2. What was the framing constructed by experts in relation to the use of fertilisers, and how did this function epistemologically and politically in policy-making arenas of the period?

3. What were the conceptual transformational changes in vision, and how were those linked to institutional authorities, professional identities and the political aspirations of experts seeking to participate in regimemaking in the field of agriculture?

By addressing these questions, this article aims to study the politics of expertise and the co-production of sociotechnical imaginaries, expertise identities and public policies in agriculture and the use of fertilisers in Greece between the years 1945 and 2000. By applying the concept of the co-productionist idiom, this article will study the processes of appropriation and show that they were dynamic processes in post-war Greece. ${ }^{4}$ The study argues that experts functioned not only as mediators but as promoters and shapers of sociotechnical imaginaries in Greece, and that they directed specific policies in promoting or controlling the use of fertilisers: particularly $\mathrm{N}$ fertilisers. The aim is not to provide a comprehensive

\footnotetext{
4 Sheila Jasanoff, "The Idiom of Co-production," in States of Knowledge: The coproduction of science and social order, S. Jasanoff, ed. (London and NY: Routledge, 2004), 1-12.
} 
study of the roles and performativity of all the stakeholders and industrial interests. The article's aim is to provide a preliminary study of the role of experts, mostly agronomists and soil scientists, in shaping sociotechnical imaginaries, directing policies and contributing to the making of sociotechnical regimes.

\section{EXPERTS, ENVIRONMENT AND REGIME MAKING:}

\section{A HistoriograpHICAL APPROACH}

The agricultural transitions and the shaping of the regime in postWorld War II European agriculture are defined both by the quest for productivity and contribution to the economy, as well as the notion of environment and the understanding of the management of commons. Agricultural transitions have been defined and structured on the co-production of environment and agricultural economies. Recently, historians of technology Disco and Kranakis have applied the concept of "sources under regimes," an approach originally introduced by Paul Josephson. ${ }^{5}$ They argue that we need to understand the conceptualisation and the development of practices relating to the management of natural resources within the framework of sociotechnical regimes that are in the process of transformation. Since the mid-nineteenth century, commons, specifically natural commons, have been acquiring meaning, value and use within sociotechnical regimes. ${ }^{6}$ By adopting their approach in studying agricultural transitions, we can understand agricultural resources like agricultural lands, or the water for irrigation as sociomaterial and historical constructs that acquire meanings within sociotechnical regimes. Natural resources have been part of the emerging "sociotechnical imaginaries," and thus part of the "collectively imagined forms of social life and social order reflected in the design and fulfilment of nation specific scientific and or technological projects." 7 The emergence of sociotechnical imaginaries legitimized the specific understanding of problems, shaped relevant policies, and directed activities for the valorisation and exploitation of the environment. ${ }^{8}$ The imaginaries are powerful cultural and political resources and as such, this article locates the

\footnotetext{
5 Nil Disco and Eda Kranakis, Cosmopolitan Commons (Cambridge, Mass.: MIT Press, 2011), 20, 30-31.

${ }^{6}$ Disco and Kranakis, Cosmopolitan Commons, 1-53.

7 Sheila Jasanoff and Sang-Hyun Kim, "Containing the Atom: Sociotechnical Imaginaries and Nuclear Power in the United States and South Korea," Minerva, 2009, 47: 120.

8 Jasanoff and Kim, "Containing the Atom," 119-146.
} 
role of experts in their formation. Although not the sole actors, by unravelling experts' activities and framings we can research the processes and the mechanisms of the formation of these imaginaries, and begin to understand their discursive and ideological power. ${ }^{9}$ Historical and sociological analysis of science has revealed the role of experts in shaping legitimate knowledge making practices, for instance in "regulatory science" in relation to toxic substances; specifically, in relation to agrochemicals. ${ }^{10}$

Through the above analytical framework, this article studies the co-production of agricultural transition with the regime of agrochemicals in the Greek context. Statistics depicting developments in the use of agrochemicals, and specifically in the use of fertilisers in Greece have shown an increase in usage from 1945 to the mid-1980s, but since this latter date there has been a decline in the use of fertilisers (see figure 1). In contrast to an increase in the use of fertilisers in countries like China, Brazil, Argentina and India, in other countries, including Greece, there was a declining trend in the use of fertilisers. The Green Revolution of the 1960s and 1970s promoted the intense use of fertilisers and pesticides, and plant varieties that were the result of laboratory or industrial research activities, all for the purpose of increasing grain yields. The result was the "chemicalisation" of plants and soil, and soil erosion, which was particularly prevalent in the topsoil. Agriculture promoted the intense use of energy and water, with the latter in danger from both the chemicals and depletion from overuse. Thus, whereas the aim of the Green Revolution was control and domination over nature, it resulted in the destruction of the environment, and in some cases led to the countereffect of the reduction of plant productivity. ${ }^{11}$ The Green Revolution shaped agricultural patterns that were costly and unsustainable; damaging to the environment and to the sociotechnical fabric of rural

\footnotetext{
9 A similar approach has been followed by Elta Smith, "Imaginaries of Development: The Rockefeller Foundation and Rice Research," Science as Culture, 2009, 18 (4): 461-482.

10 Sainath Suryanarayanan, Daniel Lee Kleinman, "Be(e)coming experts: The controversy over insecticides in the honey bee colony collapse disorder," Social Studies of Science, 2013, 43 (2): 215-240; Carolyn Dimitri, Anne Effland and Neilsen Conklin, The 20th century transformation of U.S. Agriculture and Farm Policy. U.S. Department of Agriculture (USDA) Economic Information Bulletin, 2005, 3. Available at: http://www.ers.usda.gov/media/259572/eib3_1_.pdf (accessed 29/3/2017); Ronald Brickman, Sheila Jasanoff and Thomas Ilgen, Controlling Chemicals: The Politics of Regulation in Europe and the United States, (Ithaca, NY: Cornell University Press, 2005).

11 Praful Bidwai, "India's green revolution in crisis," Science as Culture, 1991, 2 (4): 602-612.
} 
communities. $^{12}$ Gradually, countries and transnational organisations started to promote new approaches to the environment, such as the use of natural commons and the concepts of sustainability that configured new legislative, political and cultural pressures on regime actors. ${ }^{13}$ From the 1980 s onward, national policies and the agency of national regime actors were shaped by transnational political trends, and in the case of Greece, by the European agriculture and environmental priorities and relevant policies. Experts' aspirations, visions and practices have been shaped since then, both by national interests and transnational political dynamics.

In Greece, since the late 1980s, there have been European pressures for a reduction in the use of nitrogen fertilisers, despite the concurrent policies with the agricultural subsidies that would result in excessive use of fertilizers. ${ }^{14}$ This article provides a first approach to the dynamic process of the integration of fertilisers in the Greek agriculture regime and their decline, yet not with signs of destabilisation as defined by Turnheim and Geels. ${ }^{15}$ While environmental pollution meant regime actors started to lose confidence in the use of chemical fertilisers, no real alternative emerged to substitute the dominant, yet problematic practices of fertilisation. Since the 1990s the EU's regulatory regime has

12 C. Robinson, Exposed: Europe's GM-hype in times of food and fuel crisis. Institute of Science in Society. Available at: www.i-sis.org.uk/Exposed_GMhype.php (accessed 10 July 2016); Sally Brooks, "Biotechnology and the politics of truth: From the Green Revolution to an evergreen revolution," Sociologia Ruralis, 2005, 45: 360-379; L. Busch, "Grades and standards in the social construction of safe food," in The Politics of Food, eds. M. Lien and B. Nerlich (London: Berg, 2004), 163-178; R. Fischer and S. Schillberg, eds., Molecular Farming: Plant-made Pharmaceuticals and Technical Proteins, (Berlin: Wiley VCH, 2004); Sheila Jasanoff, "Biotechnology and empire: The global power of seeds and science," Osiris 2001, 21: 273-292; Robert Kohler, Landscapes and Labscapes: Exploring the Lab-field Border in Biology, (Chicago: University of Chicago Press, 2003); Richard Milne, "Pharmaceutical prospects: Biopharming and the geography of technological expectations," Social Studies of Science, 2012, 42 (2): 290-306.

13 F. Bailey Norwood, Pascal A. Oltenacu, Michelle S. Calvo-Lorenzo, Sarah Lancaster, Agricultural and Food Controversies: What Everyone Needs to Know (Oxford: Oxford University Press, 2015), 26-41.

14 Vaclav Smit, Enriching the Earth: Fritz Haber, Carl Bosch and the Transformation of World Food Production, (Cambride Mass.: MIT Press, 2001), 139.

15 B. Turnheim, F.W. Geels, "Regime destabilisation as the flipside of energy transitions: Lessons from the history of the British coal industry (1913-1997)," Energy Policy, 2012, 50: 35-49; B. Turnheim, F.W. Geels,

"The destabilisation of existing regimes: Confronting a multi-dimensional framework with a case study of the British coal industry (1913-1967)," Research Policy, 2013, 42 810): 1749-1767. 
exercised power over the Greek state and government and so could alter policies relevant to the management of agro-chemicals. In this setting expert agronomists, chemists, soil scientists, agricultural managers, and farmers had to reconfigure their attitudes towards the regime. Nitrogen fertiliser consumption had been steadily increasing at the global level since the 1950s. In Japan, North America and Europe since the 1950s and until the early 1980s and then there was a continuous decrease in the use, a trend that strengthened further in the first half of the 1990s because of the geopolitical and constitutional changes in the former Soviet Union, a country with intensive consumption of $\mathrm{N}$ fertilisers. The continuous decrease in the industrialised economies was balanced by a parallel increase in low income countries where the extensive use of $\mathrm{N}$ fertilizers kept the overall global trends of their consumption at high levels and in growth. ${ }^{16}$ In this global context, local scientific actors legitimised conceptualisations about the environment, productivity and crop quality, linking them most frequently with fertilisation practices and dominant epistemic ideologies.

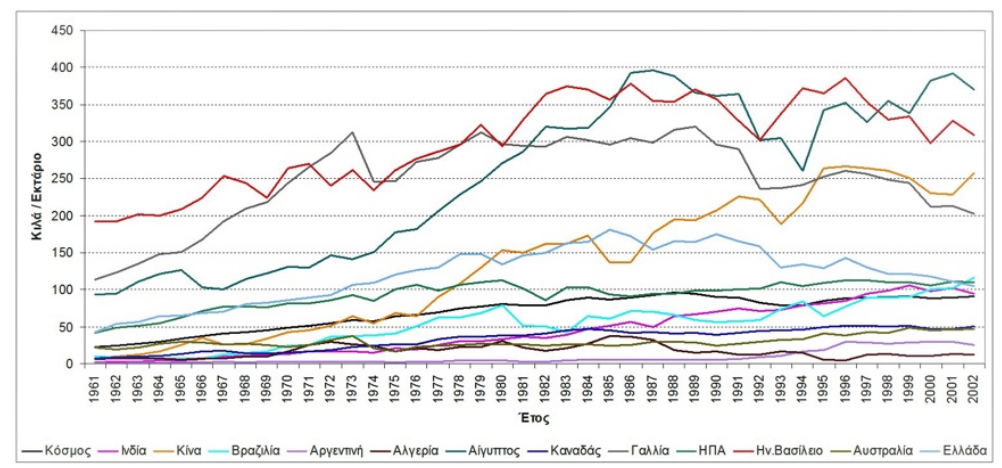

Figure 1. Use of Fertilisers 1960-2002. The light blue line shows the use of fertilisers in Greece. The years 1985-1986 show the highest consumption of fertilisers with around $175 \mathrm{~kg} / \mathrm{ha}$, while in 2002 their consumption had dropped by $75 \mathrm{~kg} / \mathrm{ha}$. Source: FAO retrieved from http://www.envedu.gr/Chapters.aspx?id=125 (last accessed 20/08/2016)

\section{BUILDING THE SOCIOTECHNICAL IMAGINARY: MEDIATING EXPERTISE AND POLICY-MAKING IN THE POST-WAR YEARS}

The period 1920 to 1980 was an era concerned with the quest of sovereignty and autarky in Greek agriculture. Emphasis was placed on "scientific rationalism," with a focus how applied science could change Greek agriculture towards intensification and

${ }^{16}$ Smit, Enriching the Earth,133-134, 140-144. 
mechanisation. State-planned and implemented policies were developed, and since the transition was state-led, state-funded research institutes into plant varieties and plant breeding, the Central Committee of seed production, state fertilisation policies, and the Greek Bank of Agriculture were responsible for financing the technological transformation of Greece's agriculture. From the 1950 s to the 1970 s the public expenditure in agriculture was as high as between $22-26 \%$ of the GDP, but by the 1980 s this had decreased by roughly $10 \% .{ }^{17}$ Since the late 1970 s and 1980s, Greek agriculture has undergone a process of liberalisation, while concurrently the integration of the legislative culture of Greece and the EEC (later the EU) has contributed to the pressing of regime actors in specific directions that have defined farming practices and agrarian transitions in the country. ${ }^{18}$

In relation to the use of agrochemicals, specifically the use of fertilisers, the period from 1945 to the mid-1980s were years in which a science-based agricultural ideology dominated. The years between 1945 and the mid-1980s were a period of social and political legitimisation of over-fertilisation and exploitation of the use of fertilisers. This bold planned policy was followed by different governments with different political and ideological inclinations. This was in stark contrast to the fertilization policies implemented in the interwar period. The key player in that period, with a privileged position that influenced policy-making, was the Hellenic Chemical Products Fertilisers Co. Ltd. ${ }^{19}$ The Hellenic Company,

\footnotetext{
17 A. Moisides, "The agriculture issue in the $20^{\text {th }}$ century" in Greece in the $19^{\text {th }}$ and $20^{\text {th }}$ century (in Greek), eds., A. Moisidis and S. Sakelaropoulos, (Athens, 2010), 289312; A. Moisidis, Agriculture Society and Modern Greece (in Greek) (Athens, 1986); S. Petmezas, "Agriculture and Economic Growth in Greece," paper presented in the IEHC Conference, Helsinki, 2006, 1-20; S. Damianakos, "The ongoing quest for a model of Greek Agriculture," Sociologia Ruralis, 1997, 37 (29), 190-208; G. Mergos and G. Karagiannis, "Sources of productivity change under temporary equilibrium and application to Greek agriculture," Journal of Agricultural Economics, 1997, 48: 313-329; P. Fousekis and C. Pantzios, "Output price risk and productivity growth in Greek agriculture," Spoudai, 2000, 50 (3), 106-124; E.C. Mamatzakis, "Public infrastructure and productivity growth in Greek agriculture," Agricultural Economics, 2003, 29: 169-180.

18 Damianakos, "The ongoing quest;" L. Louloudis and N. Maraveyias, "Farmers and Agricultural Policy in Greece since the Accession to the European Union," Sociologia Ruralis, 1997, 37(2): 271-286; D. Damianos and K. Hassapoyannes, "Greece and the Enlargement of the European Union," Sociologia Ruralis, 1997, 37 (2): 303-312; C. Rutz, J. Dwyer and J. Schramek, "More New Wine in the Same Old Bottles? The Evolving Nature of the CAP Reform Debate in Europe, and Prospects for the Future," Sociologia Ruralis, 2013, 54 (3): 266-284.

19 Eleni Maistrou, Dimitra Mavrokordatou, Giorgos Mahairas, Nikos Belavilas,
} 
enabled by state support and patronage, had established an exceptional monopoly in the fertiliser industry, producing predominantly superphosphate fertilisers. The company's agronomists and chemists promoted public lectures, publications and researched the use of phosphate fertilisers. On the eve of World War II, the company had established "Institute N. Kanelopoulos," an industrial research institute that promoted agronomy and soil science research and evidence-based agriculture in relation to fertilisation. $^{20}$ In the 1940 s and 1950 s, varieties of fertilisation practices existed with the use of both organic and inorganic fertilisers. The former gradually began to be marginalized, while the latter (inorganic fertilisers) were identified by the experts as the key means by which to increase productivity in agriculture during the post-war reconstruction of the country.

In the aftermath of World War II and the Greek Civil War (1946-1949), expert chemists and agricultural scientists put forward similar arguments to $\mathrm{N}$. Kanasis, who argued in his highly established book General Fertilization (1949) that the use of fertilisers should be increased in $80 \%$ of Greece's cultivated fields since the amount of $0,62 \mathrm{mgr} / \mathrm{ha}$ was stressed to be the lowest among other agricultural European countries (see Table 1). ${ }^{21}$ Kanasis was an officer in the Unit of Fertilisation in the Ministry of Agriculture and his aim was to diffuse knowledge and methodologies for what he deemed appropriate for a "rational" fertilisation practice. He argued that Greek agronomists were lacking substantial exposure to western practices of fertilisation. He viewed the use of fertilisers as a necessary and integral part of the regime of agricultural intensification that was sought by both local experts as well as American experts who were involved in the reconstruction of Greece during the Marshall Plan. ${ }^{22}$ Kanasis stressed that lowproductivity farming should not be compensated for and that "agriculture owes to be intensified with chemical fertilisation as at the basis of the intensified exploitation of soil and the increased productivity per square meter." 23 Science-based agriculture was promoted as the agricultural paradigm that would increase

Lida Papastefanaki and Giannis Polyzos, The Hellenic Chemical Products Fertilizers Co Ltd (1909-1993) (Athens, 2007), 25 (in Greek).

${ }^{20}$ Maistrou et al. The Hellenic Chemical Products, 34-41, 126-129.

${ }^{21}$ Kanasis, General Fertilization, (Athens, 1949) (in Greek).

22 Stathakis, The Truman Doctrine and the Marshall Plan: The history of the American aid in Greece (Athens, 2004) (in Greek).

${ }^{23}$ Kanasis, General Fertilization, 8. 
productivity when farming new plant varieties and extensive fertilisation policies.

\begin{tabular}{|l|l|}
\hline Countries & Fertilisers $\mathbf{~ m g r} /$ ha \\
\hline Greece & 0.62 \\
\hline Spain & 2.03 \\
\hline Italy & 2.21 \\
\hline France & 3.13 \\
\hline Germany & 8.92 \\
\hline Belgium & 13.99 \\
\hline Holland & 28.34 \\
\hline
\end{tabular}

Table 1. Use of fertilisers in different countries in 1949

(Source: Kanasis, 1949:16)

Kanasis promoted the view that fertilisation, while important and necessary, should not be considered effective and efficient under all circumstances. The context and local conditions mattered and should be taken into consideration. He also argued that a more systemic and comprehensive understanding and approach to agriculture was necessary to secure the implementation of intensive fertilisation policies. He argued that human control over farming and agricultural practices was important and could be secured by a, the selection of the appropriate improved seeds for local conditions; $b$, the planting of appropriate plant varieties in different types of soil; c, the control of the humidity and the quality of the soil through appropriate irrigation and organic fertilization, as well as by guaranteeing the existence of a small yet critical amount of $\mathrm{CaCO}_{3}$. Under these conditions, fertilisers could perform in the most efficient way, without tremendously increasing the cost of farming. ${ }^{24}$ It is important to point out that in the post-War period, while the emerging ideal promoted extensive intensification, Kanasis introduced conditions that would legitimise the combination of inorganic and organic fertilisation on a large scale. Existing and well-established practices such as organic fertilisation, crop rotation and the use of waste plants to increase calcium in the field, were deemed important for securing the quality of the soil before it was further boosted using chemical fertilisers. ${ }^{25}$

\footnotetext{
${ }^{24}$ Kanasis, General Fertilization, 11.

${ }^{25}$ Kanasis, General Fertilization, 11-13.
} 
In 1959, a committee of experts reported to the Ministry of Agriculture's Committee of Primary Production. The expert committee was comprised of scientific authorities including D. Katakouzinos (Director of the Soil Laboratory of the Ministry of Agriculture), N. Kanasis (Director in the Ministry of Agriculture) and I. Charpantidis (Agronomist in the Bank of Agriculture). ${ }^{26}$ They reported on the use of fertilisers in Greece, promoted the intensification of the use of fertilisers, the establishment of new and improved research institutes, and the implementation of new national policies. The use of fertilisers in just 35\% of the cultivated farms was deemed too low, and was considered the main reason for the low productivity and performance of Greek farms. This was viewed as a particularly pressing problem for improving olive, vegetable and fruit farming. The committee argued the importance of the continuation of policies to promote fertiliser use, and the need for state subsidies in order to stabilise prices at the lowest possible level. At the same time, the committee emphasised the need for an increase in the state funding of soil science, as well as in the number of distribution centres under the coordination of the Agriculture Bank. This was believed a necessary condition for the "rational" use of fertilisers. The institutional renovation and enforcement of the Central Laboratory of Soil and the investment in infrastructures and personnel were prerequisites for the development of a "Centrally Planned Fertilisation Scheme." The scheme would be based on the results of soil analysis and on an understanding of the characteristics of local soils. The proposal for a "Centrally Planned Fertilisation" scheme involved strong state intervention through the expansion of the network of soil analysis labs, investment in experimental and technical equipment, and the establishment of a new group of experts of at least 50 scientists (chemists and agricultural scientists), 30 technicians and 10 administrators. From the experts' perspectives, which stressed sociotechnical imaginaries of productivity and localisation of use, fertilisation was linked to the agenda of state reconstruction and directed state agriculture policies. In order to boost the use of fertilisers, their distribution and control was effected by a stateowned organisation, the Bank of Agriculture of Greece. The state promoted the use of fertilisers by financially subsidising their use, with the aim of providing fertilisers to farmers at a cost lower than the cost of production while also exercising control over the price. Around the same time, 900 centres of distribution were constructed

26 Principal Committee of Primary Production, (Athens, 1959) (in Greek). 
in the country to implement the policies relating to the extensive use of agrochemicals in Greek agriculture. ${ }^{27}$

The committee went on to question developed fertilisation practices and criticise the relics of pre-War practices. These practices were deemed to be inappropriate and biased due to the vested interests of native industrial concerns. Most importantly they argued that the chemists and agronomists of the Hellenic Fertilisers Chemicals Company, which was the sole institution that conducted research in the pre-War years, directed state policies by exercising their power through the intensive use of propaganda. While the Central Soil Laboratory existed, its research and role was restricted and had no real impact on directing policies and influencing fertilisation practices. This was largely because its tone and direction was set by the Hellenic Company. Due to the Hellenic Company's influence, the balance had moved rather "unreasonably" towards the use of phosphate fertilisers. In the interwar period the ratio $\mathrm{N}: \mathrm{P}: \mathrm{K} \quad(\mathrm{N}=$ Nitrogen; $\mathrm{P}=$ Phosphate; $\mathrm{K}=$ Potassium) in multinutrient fertilisers was 1:3:0.46, and became 1:2:0.46 in 1938 the year before the war. ${ }^{28}$ The members of the committee insisted that the intense use of phosphate fertilisers could not be easily explained, given the variety of soil in Greece. They acknowledged the importance of the statements by those who during the 1950s argued that the ratio should become 1:1:0.46, and that the increase in the percentage of nitrogen was necessary given the Greek farming conditions. Yet they promoted the view that any standardisation was difficult since decisions should be made based on local needs and soil specificities. Trying to influence state policies, and to secure their institutional authority in the decisionmaking process, they insisted that the sole legitimate actor to claim an institutional authority in demanding and imposing the standardisation of practices, could only be the Central Soil Laboratory. $^{29}$

The committee's members used an analysis of fertilisation practices in wheat farming as an example of past malpractices and biased approaches due to industrial interests. In the post-War period the wheat productivity that was linked to Greece's ability to be self-sufficient in wheat production was a state priority. It is indicative that the committee's statements were made public in a year when the state's self-sufficiency in wheat was achieved due to

\footnotetext{
27 Principal Committee, 169-181.

28 Principal Committee, 103.

${ }^{29}$ Principal Committee, 103-104.
} 
its reliance on new plant varieties and the use of fertilisers. Since the interwar period, intensive experimentation had been conducted for the introduction of new plant varieties in state research institutes such as the Institute of Plant Varieties and Improvement and the Cotton Institute in Thessaloniki. Systematised plant breeding was promoted as the key scientific activity to improve Greek agriculture and to secure productivity in the period after WWII, when priorities were focused on the nutrition of the population and the reconstruction of the country's primary and secondary sectors. ${ }^{30}$ Based on data produced by the Central Soil Laboratory, the committee argued that when the N:P rate was $1: 1,48 \%$ of experimental farms showed an increase in their productivity, yet when the rate was 1:2,17.3\% of the farms showed an increase. The emphasis on the use of phosphate fertilisers was insubstantial given that $82.74 \%$ of the experimental farms showed the impact and influence of the use of nitrates in the productivity of soil and the farms. They argued that a ratio of 1:1 would have been the most appropriate and scientifically robust suggestion. This argument was based on the existing local particularities of Greece, such as the warm climatological conditions and the chemical constitution of soil in most of the Greek regions, which contain such vast amounts of calcium $(\mathrm{Ca})$ that organic materials quickly decompose and lose their nutritional value. ${ }^{31}$

\section{DOMINANT FRAMINGS AND THE POLITICS OF EXPERTISE SINCE THE 1970s}

The quest to increase the use of fertilisers in farming continued during the 1970s and the 1980s. During the Junta period (19671974), under the militaristic framework of the Regime of the Colonels, the aim was to increase the use of chemical fertilisers as

${ }^{30}$ I. S. Papadakis, The Greek Plant V arieties of Wheat, (Thessaloniki, 1929) (in Greek); P. Zoiopoulos, Two Blades of Grass (in Greek), (Athens, 2014), 145-157, 194-196; 45 Years of State Seed Production (in Greek), Ministry of Agriculture, (Athens, 1974), 7-8; M. Mazower, Greece and the Inter-War Economic Crisis, (Oxford: Oxford University Press, 2002); I. Nouaros-Mihailides, "Forward to 'The Greek Economic and Agriculture Miracle'," Academy of Athens, (Athens, 1983), 556-557; Th. Dianelis, "Forward to "The Greek Economic and Agriculture Miracle" (in Greek), Academy of Athens, (Athens, 1983), 557-562; I.S Papadakis, The Greek Economic and Agriculture Miracle (in Greek), Athens Academy, (Athens, 1983); A. Ioannides, The evolution of wheat cultivation: 1919-1995 (in Greek), (Thessaloniki, 1996); C. Kribas, "Science, Technology and the Environment," in Greece in the Twentieth Century, eds. Th. Couloumbis, Th. Kariotis, F. Bellou (London and NY: Frank Cass, 2004).

31 Principal Committee, 1959, 104-105. 
part of an ideology of science-based agriculture and "scientific and techno-nationalism." The latter was developed as part of the nationalist ideology of the period. Between 1970 and 1972 there was an increase in the production and use of fertilisers by $20 \mathrm{kgr} / 0.1$ hectar. With the restoration of democracy, the governmental and state policy continued to increase the use of fertilisers by $60 \%$. In the 1970s and 1980s the quest for an accurate soil map was promoted as the necessary technology for a "rational" fertilisation. The period from 1971 to 1981 were years of planning and the implementation of systematic programmes of fertilisation research. This involved ten years of experimentation and monitoring of the fields of Research Institutes, work in real conditions, as well as engagement with farmers and local groups of practitioners. It was a scheme funded by the Scheme of Public Investments and comprised the participation of 22 research institutes and 40 agriculture departments in prefectures around the country. The experiments were conducted in 160 experimental stations with 492 trial fields. This was a mediating innovation between the experimental research stations and the local farmers. The programme involved intense social engineering in relation to the results, and public engagement in the diffusion of information and the popularisation of experimental results. The scheme also involved practices for the distribution of productivity credit of the trial fields with relevant certificates, as well as a seminar series featuring agronomists and agriculture scientists. ${ }^{32}$

In the 1970 s a new dimension to the "rationalisation" of fertilisation started to emerge. In the public discussion at the 1 st Geotechnical Research Conference (1973), soil scientist J. Argyriadis promoted the investment of human and financial resources in soil science research. He emphasised the need for investment in the soil science research that studies the linkage between soil conditions and productivity in agricultural production. He promoted the idea of collaboration between the institutions of Wheat and Cotton and the centres/stations of Soil Research. This was deemed the appropriate strategy with which to remedy the chaos caused by the multiplicity of fertilisation practices, the dominance of practical knowledge and the variety of local conditions. By investing in soil research, the state expected accurate soil maps to be produced that could function as the "technologies" for scientific fertilisation. In order to further forge his ideas, Argyriadis insisted that existing analysis could prove that the $\mathrm{P}$

32 Zaragas, Th., Chatziaslani, Chr., Velemi, D., Aggelidi, A., Fertilizers and Fertilization, (Athens, 1979). (in Greek) 
fertiliser was not always necessary to all localities. S. Tsitsamis argued that the soil map could be introduced for the rational fertilisation and rational nutrition of the plant. He argued that fertilisation needed to be conducted by taking into account the factor of nutrition. He insisted that the use of fertilisers could damage agricultural products, the nutritional value of plants and food, and vitamin A levels, and that the overuse of nitrates could be potentially dangerous. E. Gelekis, from the Livestock Development of the Prefecture of Thessaly, pointed to research from France and other European countries to support a reduction in the use of synthetic fertilisers in the cultivation of forage plants and meadows, and in order to improve the quality of livestock. Soil scientist A. Pierrakeas argued that $\mathrm{P}$ fertilisers were not always necessary or efficient in the cultivations, and instead supported the use of a new dose of $\mathrm{P}$ in the fertilisers, promoting the 16-5-0 type from the established 16-20-0. ${ }^{33}$

Despite the emergence of concerns about the risks of using excessive fertilisers during the 1980s and early 1990s, the dominant expert views stressed the need for improvements in fertilisation practices in order to achieve the highest degree of efficiency. The period from 1980 to 2000 was marked by Greece's Europeanisation. State institutions and individual scientists were bound by and responded to EU Directives relevant to the environmental impact of fertilisers and the degradation of impacted water sources. Whereas in the 1970 s environmental sensitivities were marginal, since the late 1980s and early 1990s, expert consensus had emerged locally over the understanding of the "harmful" effects of $\mathrm{N}$ fertilisers. This process was gradual. Dominant framings of the fertilisation problem by soil experts and agronomists provided an understanding of the use of fertilisers. They showed that there was a problem in the efficiency of $\mathrm{N}$ fertilisers when trying to improve the productivity of soil and plants. "Efficiency" and "rationalisation" discourses were co-produced with scientific authorities and institutional roles in the making of research policy and regulatory science. Furthermore, Greek agriculture was an important part of the national economy. This is evidenced by the fact that from 1989 the number of farms in Greece remained as high as 923,510 (almost a tenth of the total EEC number). ${ }^{34}$ Moreover, in the 1980 s almost $13.2 \%$ of the GNP in Greece was from agriculture while in the EEC the figure was only $2.3 \%$. Changes that would involve the radical transformation of

33 Proceedings of the $1^{\text {st }}$ Geotechnical Conference, 1973.

34 Damianakos, “The Ongoing Quest," 192. 
practices were less likely to achieve social and political legitimacy, particularly under the governance of the populist socialist governments of the Panhellenic Socialistic Movement (PASOK) in the $1980 \mathrm{~s}^{35}$

A.D. Simonis, a soil scientist from the Soil Research Centre in Thessaloniki, argued that "The response to the environmental problems is not the reduction of the consumption of nitrate fertilisers. This is impossible. The response is to find ways so that the plants would absorb fertilisers in the most efficient way." ${ }^{36}$ While he acknowledged the detection of nitrate pollution (19771982 and 1983) in underground waters in Attiki and in the Langada area in the prefecture of Macedonia on the outskirts of Thessaloniki, he advised "More fertilisers in the plants, less in the environment." ${ }^{37}$ Simonis tried to define a boundary between scientific and practical knowledge in fertilisation. For him this boundary was the critical way to legitimise the continuation of intense fertilisation practices within a framework of scientification. He attempted to legitimise soil research on "scientific" principles, viewing them as a necessary parameter for the rational exploitation and use of natural resources and the agricultural development and growth of the country. He argued that practical knowledge was linked to fragmented fertilisation practices and policies, and to a type of fertilisation of uncertain and precarious quality. The latter resulted in the unnecessary use of fertilisers and severe mistakes in the fertilisation policy, as well as risky practices that damaged the quality of agricultural products and resulted in soil contamination. ${ }^{38}$ He identified soil research as the key means to secure efficient fertilisation policies and provided several research priorities. These included the development of the assessment of the methods of identification of N-P-K in the soils around Greece; the identification of the accurate dose of $\mathrm{N}$ in relation to the qualityperformance indicators; the identification of $\mathrm{NO}_{3}-\mathrm{N}$ in the profile of the soil of farms. The study of the interaction of $\mathrm{N}$ with $\mathrm{H}_{2} \mathrm{O}$, and the study of the repercussions of an excess of $\mathrm{N}$ in the quality and quantity of agricultural products. ${ }^{39} \mathrm{He}$ promoted long-term

\footnotetext{
${ }^{35}$ Damianakos, “The Ongoing Quest," 192 and 197-198.

36 A.D. Simonis, "Soil Science Research in Greece: Problems and Prospects" (in Greek), Proceedings of the National Conference of Agriculture Research: Plant Production, Thessaloniki, 5-7 February 1990, (Thessaloniki, 1992), 293.

37 Simonis, "Soil Science Research in Greece," 293.

${ }^{38}$ Simonis, "Soil Science Research in Greece," 287.

${ }^{39}$ Simonis, "Soil Science Research in Greece."
} 
studies and experiments for studying the action and role of $\mathrm{P}$ and $\mathrm{K}$ in the intensified agricultural systems. ${ }^{40}$

Simonis supported a national plan of fertilisers based on developed "models" for use in various soils. Promoting further scientification of Greek agriculture by insisting on a "rational" use of $\mathrm{N}$ fertilisers, he concurrently aimed to secure the interests and professional activities of soil researchers. A science-based fertilisation policy would secure the efficient use of $\mathrm{N}$ fertiliser as a national priority for economic and environmental purposes. He supported his view by stressing that the increase in the efficient use of $\mathrm{N}$ in the cereals resulted in the saving of 120,000 tonnes of $\mathrm{N}$ during the year 1989. He acknowledged that over-fertilisation had resulted in a reduction of the productivity of crops. Yet at the same time he believed that soil science research should have been a substantial factor for competitive agriculture, and promoted as a response to those skeptical of fertilisers and supporters of organic farming. He argued that while opposition to the use of fertilisers was understandable, the response should not include legislative measures reducing the use of fertilisers. Rather, he argued for the "rational" use of fertilisers since fertilisers are necessary for the quality and productivity of the crops. In an attempt to clear fertilisers from any allegations of toxicity, he dubbed them the "nutrition of our food." 41 Simonis argued that the remedy for any drawbacks or hazardous effects from fertilisers should have been addressed by the institutional and financial state support for soil research. The lack of systemic scientific research and relevant laboratory infrastructures increased the vulnerability of the Greek state and society from the impact of the use of fertilisers and agrochemicals. He argued that fertilisers were not inherently hazardous. It was malpractice and misinformed use that made fertilisers potentially harmful for the environment. He identified a series of research priorities that should direct relevant policy decision-making. He even talked about "national problems" that should define soil research in Greece. These were the lack of a national soil map; ignorance about the efficient use of nitrate fertilisers in conjunction with the efficient use of water; the lack of research results on the processes of biological absorption of nitrates in the soil, as well as the effects of erosion on different landforms. ${ }^{42}$

\footnotetext{
40 A. D. Simonis, "Studies on Nitrogen use efficiency in Cereals" (in Greek), Proceedings of the 2nd National Conference of Soil Science, 26-27 November 1987, Greece, (Thessaloniki, 1991), 27-48.

41 Simonis, "Soil Science Research in Greece," 291.

42 Simonis, "Soil Science Research in Greece," 286.
} 
Research policies, strategies and infrastructures along those lines would have contributed to the improved use of $\mathrm{N}$ fertilisation by: a, the implementation of rational fertilisation and gradual use of $\mathrm{N}$; $\mathrm{b}$, the introduction of new technologies of fertilisers that secure slow dilution; and c, the reduction of the nitrification process. ${ }^{43}$ For Simonis, support for "rational" fertilisation was an attempt to mark the territory of the emerging discipline of soil science in Greece. The public statements functioned as boundary work for the emerging epistemic community of soil scientists. The Greek Association of Soil Science had been founded in 1984, and a science policy along Simonis' suggested direction would secure the social, epistemological and regulatory legitimisation for soil scientists, and most importantly, for those who acted in state-funded research institutes.

The first conferences organised by the Greek Association attracted the interest of the emerging community of soil scientists, as well as chemists and agronomists who were researching the productivity of farming, albeit along different methodologies and epistemic paradigms. John Papadakis, the authoritative voice in soil and agricultural sciences in Greece, argued at the $2^{\text {nd }}$ Panhellenic Conference of the Greek Association of Soil Science in 1987 that although nitrogen was important and vital in the nutrition of plants and soil, due precautions should be developed about its use and appropriate practices. He stressed, based on experiments conducted by the Cotton Institute during 1984 and 1985 that watering the soil would result in the drastic yet temporal decrease of nitrogen, which was not the result of leaching. Since it was implied that after sowing farmers used to water their fields, his suggestion involved the use of fertilisers not just after sowing but at a later stage, to avoid the temporal reduction of nitrogen. Papadakis also introduced a new dimension by stressing the importance of the evaluation and identification of $\mathrm{N}$ in the soil before fertilisation. By 1972 he had introduced a new way of finding the exact amount of $\mathrm{N}$ through the so called "pre-test" fertilisation method. In this method a small, specified and restricted area was fertilised for two weeks and the decision about the timing and the amount of nitrogen fertilisation was made based on a comparison with the rest of the field. Papadakis reiterated his long-term aim to introduce a method for the reduction in the cost of fertilisation. Furthermore, his systematised farming model made provision for the closer relations between the farmers and researchers, as well as the development of research or experimental practices that would introduce relevant

43 Simonis, "Soil Science Research in Greece," 289. 
accuracy and a scientific approach to farming practices. Papadakis pointed out that while experience and expertise, both scientific and experiential, was broad and extensive in relation to fertilisation, this expertise did not function synergistically. This resulted either in the waste of human capital, and/or in the implementation of ad hoc and fragmented practices. He promoted a systematic understanding and practice of agriculture and argued: ${ }^{44}$

In order to use the experience of farmers the soil institutes should have specialist scientists that would visit and tour rural areas and discuss with the farmers their feedback and observations. Among farmers there are few with exceptional judgement and the discussion with them would assist able scientists to draw valuable conclusions. This is a method used widely by the big companies which provide the new technologies. The collaboration of those scientists with the laboratory researchers has contributed tremendously in great results.

While Papadakis had promoted science-based agriculture since the interwar period, he understood and acknowledged that any "rationalisation" in the use of fertilisers would necessitate both science and experiential expertise. He urged agronomists and research scientists from the existing research centres to bridge the boundary and to address the value and importance of practicebased expertise. Since 1977, the Ministry of Agriculture had sought ways to engage farmers in the implementation of the reduction of fertilisation costs. Surveys were ordered in an attempt to map the attitudes and practices developed by farmers in rural areas and were considered an important means of shaping the fertilisation regime. ${ }^{45}$

Papadakis was the only authoritative expert at that time who suggested an approach to fertilisation practices that provided space and gave roles to the farmers. Other contributors, bounded by existing institutional settings, pointed out the climatological conditions as well as the role of the plant varieties in the efficiency of fertilisers and their contribution to the productivity of crops. Soil scientists Apostolakis, Chouliaras, and Nobeli acknowledged that in the case of cereals, and specifically in the case of wheat, there was an increase in the productivity of farming by 35\% during the 1970s. ${ }^{46}$ They argued that the most important factors of that

44 J. Papadakis, "N Fertilization and Research" (in Greek), Proceedings of the $2^{n d}$ National Conference of Soil Science, 26-27 November 1987, Greece, (Thessaloniki, 1991),15.

45 Makedonia, 23/6/1979, 13.

${ }^{46}$ C. Apostolakis, N. Chouliaras, C. Nobeli, “A Study of the Utilization of N from 
increase were the genetic modification of plant varieties and crops, new farming technologies, and the role of fertilisation combined with crop protection. ${ }^{47}$ Based on reviews conducted in the experimental farms in the rural area of Thessaly, the scientists claimed that "The data indicates a considerable increase in the amount of straw in most cases as compared to the control plots and in certain cases a further small increase in the treatment which include the addition of phosphate." In turn they insisted that $\mathrm{N}$ fertilisation needed to be intensified to secure productivity, but pointed to the difficulties of this process due to the increased costs this would incur for farming. ${ }^{48}$

The issue of cost, both in production and in farming, was a pressing concern for soil scientists, agronomists and policymakers in the Greek agricultural sector. Partly this was because there were endemic regime pressures in paradigms of Western agriculture. Simonis argued, based on research from abroad, that only $50 \%$ of the $\mathrm{N}$ fertilisers could have an impact on the nutrition of the plants and thus practically influence farming productivity. The wasted $50 \%$ contributed to the increased cost of farming and to environmental risks. It was argued that: ${ }^{49}$

The problem of the efficient use of $\mathrm{N}$ in farming is complex and multifaceted and depends on other problems of agronomical, economic and environmental nature- and is at the centre of the researches this period.....At the present the efficient use of $\mathrm{N}$ is not only an economic necessity for agriculture but is a way to respond in the modern dynamic environmental problems.

Transnational pressures shaped national policies and reconfigured the actors' stance in the agricultural regime. Since April 2000, the "Code of Rational Agriculture Practice for the Protection of water from pollution due to agriculture activity" (JG B 477/6-4-2000) has been in effect, as well as the EU directive 91/676 about the protection of water from pollutants from agricultural activity. These two pieces of legislation provided the framework of the actors" activities and the fertilisation policies they developed. By 2000, the

\footnotetext{
Various N15 Fertilizer Sources and the Influence of Phosphate Fertilization" (in Greek), Proceedings of the $2^{\text {nd }}$ National Conference of Soil Science, 26-27 November 1987, Greece, Thessaloniki, 1991, 17-26, esp. 17.

47 Apostolakis, Chouliaras, and Nobeli, "A Study of the Utilization of $\mathrm{N}$ from Various $\mathrm{N}^{15}$ Fertilizer Sources," 17.

48 Apostolakis, Chouliaras, and Nobeli, "A Study of the Utilization of N from Various $\mathrm{N}^{15}$ Fertilizer Sources," 18.

${ }^{49}$ Simonis, "Studies on Nitrogen use efficiency in Cereals," 27.
} 
concept and legal category of "vulnerable zones" towards nitrogen pollution from agricultural run-offs had been introduced, and instituted initially into four areas with a total surface of 500,000 Ha. This was later expanded to include three further areas. The integrated use of fertilisers was promoted and planned with the aim of having minimal impact on the environment. Implementation began in 2000 and was obligatory for all farmers. Yet since that date, various programmes relating to the integrated plant nutrition approach have been implemented at a segmental ad hoc level. For instance, the programme implemented in Thessaly prefecture, in central Greece, has focused on the protection from erosion in hilly areas. In turn, the management programmes for lakes Volvi and Koronia, in the prefecture of Macedonia, as well as for coastal wetlands of the region of Thrace (an area of 31,200 Ha), were aimed at the management of crop residues in order to enhance soil fertility and its organic content. Since 2000 a number of national programmes in biological agriculture and integrated production have been implemented. Concurrently, biological agriculture was promoted initially for an area of 10,000 $\mathrm{Ha}$, with a view to expand to $25,000 \mathrm{Ha}$. This has since been expanded to an area of 25,000 $\mathrm{Ha}$, as a result of the integrated programme of production introduced between 2000 and $2006 .^{50}$

In the early years of the twenty first century, water pollution was a major concern for agriculture and water management experts and policy-makers. Groundwater use represented $42 \%$ of the total water demand. Major uses of groundwater included agriculture $(36 \%)$, public supply $(5 \%)$ and self-supplied industries $(1 \%)$. The overuse of fertilisers resulted in the drastic reduction of underground water due to the overexploitation of existing resources and underwater drilling infrastructures. In 1984, Professor Poulovasilis from the Hydraulics Laboratory for the University of Agricultural Science in Athens initiated experiments to enrich the underground water resources of the plain of Argos, which were contaminated: the water supply systems contained nitrates. ${ }^{51}$ While water salination started to be a concern, little was done for around 15 years. The discourses on "rationalisation" of fertilisation that we have explored in previous parts of this article directed experts' practices and scientific

\footnotetext{
50 "Natural Resources Aspects of Sustainable Development in Greece," United Nations

http://www.un.org/esa/agenda21/natlinfo/countr/greece/natur. $\underline{\mathrm{htm}}$, Accessed 07/11/2016.

51 Vima, 23 January 2000, A 25.
} 
production towards the problem of efficient use. They viewed "efficient use" as the solution to counteract the $\mathrm{N}$ fertilisers' harmful effects. Albanis, professor of Chemistry at the University of Ioannina, argued in $2000:^{52}$

Areas of more than 20 years of overuse of fertilisers would need a different strategy with technical solution for the restoration of the local natural environment and habitat. In Magnesia and in Argolida there are areas with high rates of nitrates in underground water of such extent that is dangerous not only for water supply but also for irrigation!

Anthropocentric and industrial activities had a hazardous impact on the quality of soil and water in Greek rural areas, and resulted in deprived populations. Since the 1990s, specialist programmes for the improvement of agricultural land in Greece had been introduced, mainly to respond to three major problems and pressing concerns. Firstly, the acidity of the soil due to the overuse of $\mathrm{N}$ fertilisers. Secondly, the deprivation of saline and saline sodium soils due to the overuse of existing underground water resources. The lack of drainage infrastructures forced authorities and farmers to water the plains with individual drillings that would over-exploit water resources and were also very energy intense. Furthermore, the third major problem was the contamination of both soil and water from agrochemicals (see the Groundwater in the Southern Member States of the European Union-Country Report). ${ }^{53}$ Despite the agreement of the majority of experts, the national policy remained fragmented. The programmes that were implemented in Thessaly to reduce nitrate pollution in the period 1996-2000 did result in the reduction of $\mathrm{N}$ fertilisers. This amounted to some 10 million tonnes of $\mathrm{N}$ fertilisers, encompassing a $30 \%$ reduction in the use on cotton, and $25 \%$ on tomato farms. Further "landscape pressures" from the European Commission came on 1 October 2012, when swift action was urged to further redress the situation. While Greece designated some additional Nitrate Vulnerable Zones, the Commission deemed that the response was only a partial and fragmented designation, and demanded the designation of more areas. ${ }^{54}$ In 2012 the Commission

\footnotetext{
52 Vima, 10 December 2000, 66.

53 "Natural Resources Aspects of Sustainable Development in Greece," United Nations.

54 Ag. Filintas, P. Dioudis, G. Stamatis, J. Hatzopoulos, Th. Karyotis, 2008 Environmental Assessment of Groundwater Nitrate Pollution from Agricultural wastes and fertilizers in central Greece watersheds using remote sensing and GI. 3rd International Conference AQUA 2008 on: Water Science and Technology with
} 
referred the case to the European Court of Justice in order to secure Greece's alignment with European regulatory framework. As we saw in the introduction, this court case resulted in the condemnation of Greece.

\section{CONCLUSION}

In this article, I have shown the role experts played in shaping sociotechnical imaginaries in relation to the use of fertilisers. I have shown how this use was linked with the ideology of mechanisation and technological determinism in agriculture as the quest for the country's developmental paradigm continued. The latter was a policy paradigm that was served through bold policies planned by different governments with different political and ideological inclinations. Yet I argue that during the period from the end of the Greek Civil War until 1990, experts functioned as key mediators in framing, and politically and socially legitimising the use of intense fertilisation. Due to high degrees of ignorance, the experts had power and legitimacy to shape policies and legislative measures. They participated in the governing of the agricultural transition and contributed substantially by responding to the articulated pressures on the regime. In the years since 1990, they have had a restricted role in the process of regime destabilisation and the governance of transition. In this period transnational political pressures from the European Union shaped experts' consensus on the harmful effects of agriculture malpractice and the overuse of nitrogen fertilisers.

Technological determinism and the "chemicalisation" of agriculture as promoted by local experts were the driving ideological and epistemological factors in the transition of agriculture in Greece in the post-World War II era. In the first two decades after the war, emphasis was given not only to the social and political legitimisation of fertilisers as an important practice that would secure the political priorities of the period, but also to the need for the transition from phosphate to nitrogen-based fertilisers. Since the 1970s, the quest for science-based inorganic fertilisation has been initiated by new institutional authorities and new emerging epistemic communities such as soil scientists. I argue that although environmental concerns existed by the early 1980s, they remained marginal, and did not influence the scientific discourses of experts. Thus they were not addressed by public agricultural policies. Arguments about the risks and uncertainties relating to the use of fertilisers practically

emphasis on water \& climate, 16-19 October, Athens, Greece. 
disappeared, despite the fact that they existed and were developed by scientists of the period. Whereas they had an impact on shaping public techno-scientific discourses by introducing environmental factors as matters of concern, the dominant approaches promoted the "rationalisation" of use as both the remedy to environmental hazards from over-fertilisation, as well as the response to the increasing pressures for productivity in the primary economic sectors, including agriculture. It was the transnational agricultural policies of the European Union that acted as pressures on the regime actors in Greece, and in turn that shaped research and research policy in relation to the use of fertilisers in farming. European directives, with their normative implications in relation to the environmental impact of agriculture practices including fertilisation policies and the management of agricultural and water commons, influenced experts' understanding of the risky nature of inorganic fertilisation. Experts, while acknowledging the potential and possible environmental deterioration of rural environments, as well as of the biological substances of agricultural products, still promoted the scientific remedy of "rational" fertilisation. Despite a legal defeat in the European High Court and the need to promote a more environmentally friendly agricultural paradigm through the enforcement of new and expanded regulatory tools, the dominant public discourse promoted by experts in Greece still prioritised accuracy and rational use.

\section{ACKNOWLEDGEMENTS}

I would like to thank José Ramón Bertomeu Sánchez, Ximo Guillem-Llobat and the participants of the 8th $^{\text {th }}$ European Spring School on History of Science and Popularization: "Living in a Toxic World, 1800-2000," for comments on earlier versions of the article. I am grateful to Ignacio Suay-Matallana, Ana Maria Carneiro and the anonymous referees for their suggestions. I would like to thank, for their invaluable assistance with archival sources, the librarians and archivists of the Library of the Ministry of Agriculture, the Library of Benaki Phytopathological Institute and Dr. Sideris Theocharopoulos from the Soil Institute of Athens.

Publishing expenses of this article were paid in the context of the project UID/HIS/00286/2013. 